\title{
A Trilogia Matrix: Estratégias de Enunciação Sincrética em Textos Cinematográficos
}

\section{The Matrix Trilogy: Strategies of Syncretic Enunciation in Cinematographic Texts}

\author{
Nilton Hernandes ${ }^{1}$
}

Resumo: Este trabalho apresenta uma reflexão sobre o texto sincrético cinematográfico. Procura mostrar, a partir de exemplos da Trilogia Matrix, a existência de uma sintaxe do cinema padrão Hollywood, que pode ser entendida como uma estratégia de enunciação organizada a partir dos recursos de câmera e de edição, cuja missão é administrar como o público deve sentir e reagir, evidenciando ou desvalorizando certos aspectos da narrativa.

Palavras-chave: Matrix, sincretismo, câmera, edição, cinema

\begin{abstract}
This work presents a consideration about the cinematographic syncretic text. Using The Matrix Trilogy as an example, this work shows the existence of a cinema syntax that is based on the way that Hollywood makes films. This syntax can be understood as one strategy of enunciation which is organized from camera and edition resources, whose mission is to manage the way that the public must feel and react, evidencing or devaluating certain narrative aspects.
\end{abstract}

Key words: Matrix, syncretism, camera, edition, cinema

${ }^{1}$ Doutorando USP - trabalho realizado com o apoio da FAPESP. 
Filmes são semióticas sincréticas. Manejam vários conjuntos significantes - música, ruídos, falas, gestos. Para a semiótica de Greimas e de seus seguidores, a produção cinematográfica não é uma reunião de "pedaços", mas um "sistema de relações" que resulta em um "todo de sentido". Entender como esse fenômeno acontece não só em filmes, como em outros textos sincréticos ${ }^{2}$ jornalísticos, artísticos, publicitários, por exemplo - é um desafio para os semioticistas. Tentaremos, neste trabalho, uma compreensão um pouco maior do sincretismo em filmes buscando exemplos na Trilogia Matrix, ${ }^{3}$ que representa bem o hegemônico cinema padrão Hollywood. $^{4}$

Vamos pensar o fenômeno do sincretismo neste trabalho como profundamente ligado e dependente das estratégias de manipulação que envolvem enunciador e enunciatário. Um filme, por exemplo, tem como coerção ser atraente para motivar o consumo no cinema ou na TV. No processo de fruição, também precisa agradar a quem lhe assiste. A reunião de diferentes conjuntos significantes por um enunciador é, portanto, parte de uma estratégia cuja finalidade maior é a captura e a manutenção da atenção do enunciatário. Só há sucesso - e faturamento desejado - se essa ligação público-sujeito/obra-objeto efetivamente ocorrer. O sincretismo - ou o uso de diversas linguagens de manifestação que caracterizam um filme - deve ser entendido a partir dessa necessidade de o enunciador buscar e manter laços com seu enunciatário, de "gerenciar a atenção" do espectador. Mais do que um "espectador”, o sujeito deve ser também um “expectador”, alguém que, manipulado pelo texto, passe a ter expectativas, curiosidades que demandam satisfação e façam com que se mantenha ligado à tela do começo ao fim da projeção. Iremos, a seguir, estudar um pouco como funciona o que chamamos de "gerenciamento do nível de atenção" do público para abordar melhor o fenômeno do sincretismo como parte integrante dessa estratégia.

A atenção do público em produtos do tipo Matrix é manipulada de duas maneiras principais que estão intimamente relacionadas:

1 - A primeira diz respeito à narrativa, à construção do enunciado, que, para ser eficaz, deve fisgar o espectador pela curiosidade, uma paixão simples, ligada a um "querer-saber" ou um

\footnotetext{
2 Quando falamos aqui em "texto sincrético", ou "objeto sincrético", queremos sempre remeter a uma idéia inicial: a de um objeto que produz sentido a partir da manifestação de diversos conjuntos significantes. O sincretismo não é exatamente um tipo de texto, mas uma característica de construção discursiva.

${ }^{3}$ A Trilogia Matrix inclui os filmes Matrix, Matrix Reloaded e Matrix Revolution, concebidos e dirigidos pelos irmãos Wachowsk. O primeiro lançado em 1999; e o segundo e o terceiro, em 2003.

${ }^{4}$ Em função dos limites e objetivos deste estudo, vamos refletir mais sobre algumas estratégias de expressão do cinema e as relações de maior amplitude entre planos. Quem estiver interessado em conhecer a análise da Trilogia Matrix deve procurar nosso trabalho no site http://niltonhernandes.sites.uol.com.br
} 
“querer-resolver”. Em outras palavras, o público deve adquirir o desejo de desvendar, conhecer, investigar até o fim da trama. O grau máximo de tensão dessa curiosidade é conhecido como "suspense". É interessante pensar que a curiosidade cria uma sensação disfórica, uma ansiedade que precisa ser manipulada com cuidado pelo cineasta.

Desde o teatro grego, o esquema típico de uma história tem três partes principais (COMPARATO, 1983, p. 53):

o apresentação do conflito - alguma coisa que acontece rompe uma determinada harmonia;

o desenvolvimento do conflito - a busca pela retomada da harmonia;

o solução do conflito - a recuperação da harmonia.

2 - A segunda forma de manipulação da atenção do público vincula-se a uma expectativa ligada à enunciação, ao modo como a história vai ser contada.

Essa motivação está centrada no processo enunciativo. O cineasta confia em uma memória do público, que gera certas ansiedades do que ver e como ver. Nesse sentido, nenhuma produção do cinema contemporâneo é mais dependente dos efeitos especiais do que a ficção científica. $\mathrm{O}$ espectador desse tipo de filme espera ser "maravilhado" por uma produção eficiente. Os efeitos, mais do que meios de encantar, devem ser encarados como verdadeiras coerções do gênero.

O espectador vive, portanto, essas duas expectativas. A primeira é a de participar de um jogo em que fica exposto um lado que poderíamos chamar de mais inteligível, passional. O enunciatário assume um papel quase de detetive, tentando antecipar o que vai acontecer. A segunda expectativa é mais sensorial, ligada, por exemplo, à necessidade de se encantar com aspectos estéticos, de movimentação. No caso de um filme de ficção científica, isso significa querer ver efeitos mirabolantes, lutas coreográficas, robôs reluzentes, explosões espetaculares. Não sem razão, o fenômeno do sincretismo nesse gênero é marcado por um enorme adensamento sensorial.

Podemos notar que, com essa pequena explicação, já abordamos algumas questões importantes, que dizem respeito a uma forma de "conteúdo" e a uma forma de "expressão" muito relacionadas e dependentes de uma enunciação bastante complexa. Sabemos que o sincretismo de linguagens é um fenômeno do plano de expressão. Historicamente, a semiótica preocupou-se com o entendimento do plano de conteúdo. E por uma razão bastante justificável. Alterações de forma de expressão não iriam impedir a história de ter um determinado núcleo perfeitamente analisável em qualquer meio de comunicação. A saga de Neo na Matrix é uma história que, teoricamente, 
poderia aparecer na forma de quadrinhos, como peça teatral, em um site na Internet. Em todas essas opções, é possível analisar o plano do conteúdo - de maior desenvolvimento teórico na semiótica francesa - com excelentes resultados. Isso porque, em qualquer caso, provavelmente teremos uma estrutura narrativa básica, os mesmos temas e figuras.

Contar a saga de Neo no cinema ou em quadrinhos, contudo, também vai mexer com diferentes ordens sensoriais, vai adicionar "alguma coisa", tirar outras. Cada mídia tem coerções e vantagens próprias. Nesse ponto, torna-se necessário enfrentar uma série de outras questões, como a do sincretismo, da textualização, das estratégias do plano de expressão, das relações entre expressão e conteúdo - os chamados semi-simbolismos. O que o manejo de diversos "conjuntos significantes" de cada meio - expressão menos comprometedora do que "linguagens" - acrescenta ou retira da história? Como manipulam os nossos sentidos? Surgem novas questões para refletir (ou antigas questões ganham nova complexidade): a estesia e o estético (o impacto do belo, ou do feio, do estranho), a emoção, o reforço de certas paixões, o ritmo. Estudar o sincretismo é, de um lado, buscar saber o que é esse "algo a mais" proporcionado pelo uso de estratégias de expressão distintas. Ao mesmo tempo, o sincretismo não pode prescindir da análise do plano de conteúdo e de tudo o que já foi conquistado pela semiótica.

Há dois problemas (armadilhas?) que se colocam diante de quem quer fazer um estudo menos fragmentário de textos cinematográficos, publicitários, jornalísticos, só para citar alguns objetos sincréticos: de um lado, é acreditar que somente uma análise do conteúdo dá conta da sua produção de sentido. De outro, é valorizar demais questões estéticas, sinestésicas, sensíveis - um "fazer-sentir" do plano de expressão - e esquecer que se relacionam a um conteúdo maior, a uma visão de mundo, a uma estratégia de persuasão, a um fazer-crer. A reflexão sobre o sincretismo, portanto, justifica-se quando há necessidade de se abordar o objeto cinematográfico de um ponto de vista mais global. 


\title{
Definições de sincretismo e relação entre planos
}

Antes de fazer algumas propostas sobre o sincretismo nos filmes, é importante retomar os conhecimentos mais estáveis sobre esse fenômeno. Uma das abordagens mais complexas e abrangentes sobre o assunto aparece no segundo dicionário de semiótica e foi formulada por JeanMarie Floch. Alguns trechos fundamentais:

\begin{abstract}
As semióticas sincréticas (no sentido de semióticas objetos, quer dizer, das magnitudes manifestadas que dão a conhecer) se caracterizam pela aplicação de várias linguagens de manifestação. Um 'spot' publicitário, uma historieta, um telejornal, uma manifestação cultural ou política são, entre outros, exemplos de discursos sincréticos. [...] Semióticas sincréticas constituem seu plano de expressão - e mais precisamente a substância de seu plano de expressão - com os elementos dependentes de várias semióticas heterogêneas. Afirma-se assim a necessidade - e a possibilidade - de abordar estes objetos como 'todos' de significação [...]
\end{abstract}

Essa definição de Floch, que impõe o conhecimento de todo o conceito de signo de Hjelmslev, apresentou, na época, importantes novidades teóricas que ainda hoje se mantêm válidas:

- Num texto sincrético, não há "soma" de sentidos, mas "relações". Não existem, também, diversos "planos de expressão" para um só conteúdo. O sentido não é gerado a partir de uma intersemioticidade, em outras palavras, como se as linguagens tivessem sentidos diferentes no texto e formas de expressão diversas.

- Floch afirma que, num texto sincrético, todas as substâncias da expressão formam um "todo de sentido", resultam em um único significado. Não entendemos um texto sincrético, como um filme, a partir da percepção que discrimina as tomadas de câmera, depois o som, os gestos, as falas.

Fontanille, por sua vez, chama tudo o que é da ordem da expressão de "mundo exterior", e o que é da ordem do conteúdo de "mundo interior" (2003, p.20). Graças ao nosso corpo, e a nossa percepção, é que reunimos esses dois planos na nossa consciência. O autor dá um exemplo bastante interessante da variação possível das fronteiras entre plano da expressão e plano do conteúdo - e devemos notar que o exemplo nem é sincrético: 
Se, por exemplo, eu observo que a mudança de cores de uma fruta pode ser relacionada com os graus de maturação dela, os primeiros pertencerão ao plano da expressão; e os segundos, ao plano do conteúdo. Porém, eu posso muito bem colocar em relação os mesmos graus de maturidade com uma das dimensões do tempo, a duração; e, dessa vez, os graus de maturidade aparecem como plano da expressão, e o tempo, como plano do conteúdo (ibid., p. 34).

Lembra então Fontanille que, no lugar de fixar a existência presumida dos dois planos em um objeto, o interesse deve se concentrar sobre a maneira pela qual essa fronteira é instituída (id.), reflexão importante para entender o cinema, como mostraremos depois. Interessa agora notar que a fronteira entre expressão e conteúdo, a passagem de substâncias para formas, depende da percepção de quem a ordena. E mais: que a percepção - ou esse "encaixe" entre expressão e conteúdo na nossa cabeça - também é manipulável por um enunciador, como no caso dos filmes.

Um filme não é apenas uma reunião de "efeitos de áudio" e "efeitos visuais", mas, relembremos, um complexo relacionamento entre conjuntos significantes diversos, sincretizados com o objetivo de obter e manter a atenção do enunciatário. São comuns análises de filmes, contudo, que se concentram em discussões sobre o conteúdo. Grosso modo, esses estudos encaram a narrativa do filme quase como um olhar apenas sobre o roteiro. Queremos investigar aqui, a partir de uma reflexão sobre o sincretismo, os efeitos dos recursos cinematográficos sobre a história, ou como o modo de enunciá-la, de "expressá-la", em que se relacionam diferentes conjuntos significantes, a afeta e a enriquece.

Citamos, há pouco, que um mesmo núcleo narrativo pode aparecer em diversas mídias. A enunciação sincrética é determinada pelas coerções e possibilidades de um meio de comunicação. Um exemplo banal: não se pode sincretizar música com imagem em quadrinhos, mas é possível tirar vantagens de canções em uma radionovela. E é isso que nos propomos a pensar de agora em diante. Discutiremos algumas características da enunciação sincrética cinematográfica.

Um das chaves para entender o processo de sincretismo cinematográfico é observar um filme como um "texto", aqui no sentido semiótico, marcado por relaç̃̃es temporais. Uma obra cinematográfica é um objeto que tem uma construção e também uma significação (possibilidades de "encaixe" entre expressão e conteúdo), determinadas a partir de uma enunciação que se dá na forma de um fluxo, de uma sucessão temporal. Em um texto cinematográfico, um enunciador pode lançar mão de vários conjuntos significantes no plano de expressão, ou seja, relacionar música, 
cenários, locuções, gestos, criando efeitos de coesão variados que modificam a carga sensorial e de significados de um elemento individualmente em favor de uma estratégia global. Essa estruturação, no entanto, submete-se a uma coerção desse tipo de texto. Como a construção se dá na forma de fluxo, o arranjo é de ordem temporal. As várias formas de "sincretização" de unidades e, depois, a organização textual final, devemos insistir, são, por sua vez, pensadas pelo enunciador com o objetivo de manipular possibilidades de percepção do enunciatário dentro da coerção maior de obter a atenção.

No cinema, para resumir, é preciso converter uma narrativa - um roteiro - em uma história que se dá na forma de fluxo. E o entendimento de que um filme como Matrix é um todo de sentido, apesar do enorme uso de "linguagens" de manifestação, vem do fato de que a hierarquia desses conjuntos significantes se dá por meio de uma estruturação temporal. Para aprofundar essas questões, pensemos a história de Matrix antes e depois dessa "conversão" como exercício teórico. Numa análise do tipo "roteiro", 5 mais relacionada ao plano de conteúdo, Matrix é contada a partir do ponto de vista do herói, Neo, em terceira pessoa (os fatos vão se sucedendo, sem necessidade de um narrador explícito). A ação se passa no futuro, apesar de a Matrix simular o tempo "presente". A categoria de pessoa gera principalmente dois efeitos. O primeiro é de objetividade caso majoritário encontrado em Matrix. O público se relaciona com “eles”, os personagens, efeito de uma enunciação que tem uma debreagem enunciva. O segundo efeito é o de subjetividade, debreagem enunciativa, não encontrado na trilogia.

Se for levado em consideração o modo de manifestação da narrativa, em outras palavras, como fica a história contada cinematograficamente, ou seja, o efeito de sua enunciação, as categorias de pessoa, tempo e espaço ganham enorme complexidade.

\section{A sintaxe do cinema: recursos de câmera e edição}

Para sair de uma análise meramente de conteúdo, e entender melhor o impacto dos efeitos expressivos do sincretismo nos filmes, é importante detalhar as formas de construção que caracterizam o texto cinematográfico. O cinema tem uma sintaxe ou uma gramática determinada pelo uso coordenado de dois recursos principais:

1. recursos de câmera - como planos, focalização, angulação, movimentos;

\footnotetext{
5 Partimos da idéia da existência de uma análise narrativa que se concentra apenas no roteiro, sem efeitos de expressão, por questão didática, porque é assim que diversos trabalhos se apresentam. Queremos ressaltar, contudo, justamente a importância de se pensar nos recursos de expressão na hora da análise dos impactos de uma história sobre o público.
} 
2. recursos de corte e edição (ou montagem).

Entendemos esses recursos como possibilidades de manejo do plano de expressão cinematográfico, com conseqüências importantes para entender como se dá o sincretismo e o manejo do conteúdo. Um exemplo muito simples: dentro de um mesmo fluxo a câmera pode mostrar atores e cenários juntos ou separados. A montagem pode apresentar separadamente ou não uma música e um personagem. Cada escolha determina um efeito diferente, que pode redundar em percepções distintas do enunciatário, e até em alterações do conteúdo. As diversas possibilidades de administrar os conjuntos significantes disponíveis podem modificar o entendimento de uma mesma história. Os recursos de câmera e edição funcionam como importantes meios de sincretização de conjuntos significantes e expõem o funcionamento do plano de expressão cinematográfico.

Há outros aspectos importantes. É a câmera e a montagem que "complexificam" as categorias de pessoa, tempo e espaço em um filme. A câmera tem a capacidade de simular uma interação do espectador com o que ele vê, portanto, influencia a actorizalização e a espacialização. Já a montagem age na temporalização. Nesta parte do texto, estudaremos alguns efeitos da câmera e a ação exercida na pessoa e no espaço, para depois nos concentrarmos na edição e como age no sentido de tempo. Deixaremos para o final do trabalho o estudo da edição do ponto de vista da manipulação perceptiva. É necessário destacar que, numa mídia de fluxo, em um objeto de manifestação temporal, como o cinema, a montagem aparece como a estratégia que acaba por reger todas as outras.

Há diversas possibilidades de criar sentido com a câmera. Vejamos:

Enquadramento - Por exemplo, deixar um objeto dentro ou fora do quadro. No cinema de terror, por exemplo, ouvir um monstro e não vê-lo causa suspense e medo.

Ângulos de filmagem - No ângulo alto, há um enquadramento da imagem com a câmera focalizando a pessoa ou o objeto de cima para baixo. "Provoca um achatamento da imagem, o que geralmente leva a uma sensação de diminuição e inferioridade. É muito usado para se criar a idéia de que alguém está 'olhando de cima' numa posição de inferioridade" (Manual de Vídeo do SENAC, [199-]). No ângulo baixo se faz enquadramento da imagem com a câmera focalizando a pessoa ou o objeto de baixo para cima. É utilizado "em situações inversas a da câmera alta, quando se quer dar a idéia de que alguém está 'olhando de baixo', numa posição de inferioridade” (ibid.). Do ponto de vista semiótico, criam semi-simbolismos. É mais comum o uso da câmera em ângulo 
plano. As pessoas ou objetos filmados são apresentados num plano horizontal em relação à posição da câmara.

Movimentos de câmera: A câmera também dispõe do recurso de mover-se. No travelling, se desloca para acompanhar uma cena, um objeto ou pessoas. No cinema, geralmente essa movimentação acontece sob trilhos. Já a panorâmica é o "movimento horizontal da câmera sobre o seu eixo vertical” (GAGE E MEYER, 1991, p. 202).

Efeitos ópticos: O zoom é o movimento de câmera para aproximar ou afastar a imagem de pessoas, objetos e cenários. Quando o movimento é de afastamento, há um zoom out. Quando a câmera se aproxima de um objeto, acontece um zoom in. Temos ainda o efeito de profundidade de campo. Pode-se mostrar um objeto e toda a paisagem atrás dele ou desfocar esse mesmo fundo para ressaltar o que está em primeiro plano.

Planos de câmera: referem-se às possibilidades de se mostrar um objeto. Pode ser de muito longe, dentro de um determinado contexto, ou de muito perto, a ponto de exibirem-se todos os detalhes. Há ainda as gradações entre esses extremos. Os planos de câmera simulam principalmente o contato de corpos do público com personagens ou objetos. No dia-a-dia, a aproximação sujeito-objeto se relaciona a atos de intimidade e também ao que desperta curiosidade e atenção. No cinema e na TV, isso acontece na forma de um simulacro. Tudo o que a câmera traz para perto mobiliza uma dimensão mais afetiva - emocional, passional ou sentimental. Já o distanciamento promovido pelo equipamento, ao contrário, tem vários efeitos interessantes. Pode ser o de observar um "quadro completo", no qual se insere a parte no todo, uma operação de caráter inteligível. O distanciamento também pode surgir como conseqüência, por exemplo, de uma curiosidade satisfeita, como se um objeto que despertou uma atenção inicial já tivesse exaurido a capacidade de atrair o sujeito.

É possível divisar, portanto, que um plano de câmera, ao simular a aproximação do enunciatário com um elemento do enunciado, gera efeito de intimidade, afetividade, tensão. Já os planos mais amplos, que expõem essa mesma unidade como parte de um contexto, impõem certos efeitos de distanciamento, distensão e inteligibilidade.

A câmera, ao registrar uma ação ou um estado, escancara a existência de um ponto de vista. Só que esse olhar do enunciador se impõe como o olhar do enunciatário. O telespectador, assim, se vê obrigado a ver o que a lente vê, e, geralmente, passa a desconsiderar tudo o mais que não entra nos enquadramentos. Para avançar no estudo dos efeitos de distanciamento e aproximação, é 
necessário conhecer tipos de enquadramento de câmera, aqui pensados tendo o corpo humano como parâmetro: ${ }^{6}$

Fig. 1 - posicionamentos de câmera

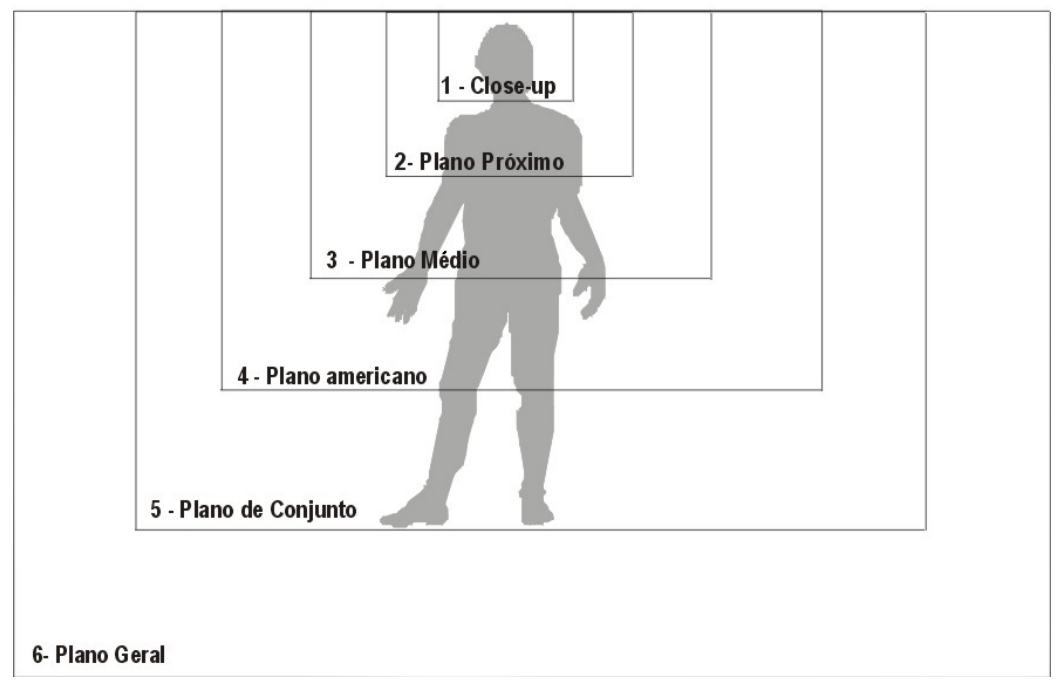

No extremo da aproximação, temos close-up ou close, que gera uma proximidade afetiva do público com algo ou com alguém mostrado na tela. O close-up

é um dos recursos mais enfáticos na linguagem cinematográfica. A câmera aproxima-se um pouco mais, mostrando apenas os ombros e a cabeça do ator. Com isso, o cenário no qual se desenvolve a ação é praticamente eliminado. E as expressões do ator tornam-se mais nítidas para o espectador (GAGE E MEYER, 1991, p.7-74).

Marcel Martin se refere a esse enquadramento como "primeiro plano", e afirma:

${ }^{6}$ Consultamos cinco publicações sobre planos de filmagem para fazer a ilustração. São elas GAGE, L. D.; Meyer, Cláudio. O filme publicitário. São Paulo: Atlas, 1991; WATTS, H. On camera - o curso de produção de filme e vídeo da BBC. São Paulo: Summus Editorial, 1990; WAIN, G. Como filmar. Lisboa: Prelo Editora, Lisboa,[s.d.] $3^{\mathrm{a} e d ;}$ Manual de Vídeo do Centro de Comunicação e Artes. São Paulo: SENAC, [199-], que não informa o autor ou autores; e MARTin, M. A Linguagem Cinematográfica. São Paulo: ed. Brasiliense, 1990. Um fato chamou a atenção. Foram encontradas enormes diferenças entre os nomes de planos de câmera. $O$ filme publicitário, por exemplo, chama de plano americano o que On Camera diz se referir ao plano de conjunto. O plano médio de Como filmar é o plano geral das outras duas publicações. Adotamos $O$ filme publicitário por ser muito mais completo e produzido no Brasil. 
Sem dúvida, é no primeiro plano do rosto humano que se manifesta o poder de significação psicológico e dramático do filme, e é esse tipo de plano que constitui a primeira, e no fundo a mais válida, tentativa de cinema interior (1990, p. 39).

Esse plano leva a uma concentração de nossa atenção. Um caso interessante de close-up é o momento em que Trinity é baleada no coração por um agente, início de Matrix Revolutions (fig. 2). Foca-se o tiro atingindo o peito e depois a expressão da mulher no seu momento de dor e de reconhecimento de que perdeu a batalha:

Fig. 2: exemplo de close-up

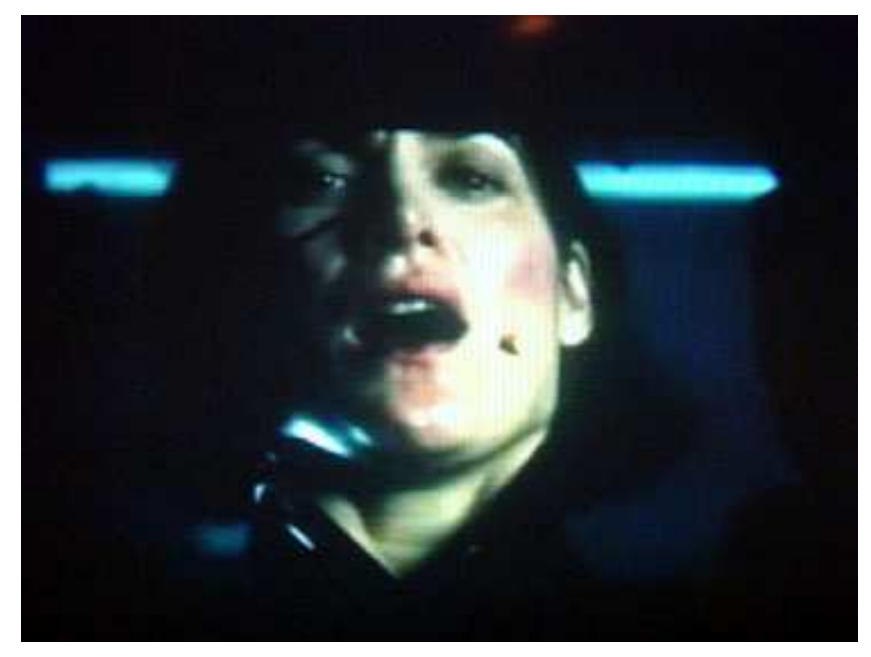

Trinity também olha para o espectador, faz uma debreagem interna. Simula, portanto, uma relação eu-tu (proporcionada pela câmera subjetiva). O efeito do close-up e do olhar direito para a câmera, entre outros, praticamente deixa em segundo plano a narrativa factual, teoricamente mais "objetiva". A câmera simula a aproximação corporal do espectador, o que gera intimidade, afetividade. Reconhecemos também no ir e vir da câmera (e das lentes) o que o enunciador quer que valorizemos. No citado close-up de Trinity, por exemplo, adensou-se ainda o momento de máxima disforia narrativa: o da possibilidade de morte da "mocinha". Não se pode pensar em efeitos de actorialização enunciativos sem levar em consideração a complexa relação de todas essas características na maneira de contar a história. Outro exemplo de close-up acontece quando Oráculo fala a Neo que o mundo pode ser destruído por Smith (o anti-sujeito) em Matrix Revolutions, num dos instantes de maior tensão do filme. Esse plano força a uma concentração de nossa atenção. 
Nesses exemplos, a câmera nos impõe a máxima atenção para as reações dos personagens. O olhar do telespectador não tem mais nada na tela para se dispersar. É como se a câmera dissesse: "Preste atenção, pois aqui está um momento muito importante - e tenso - da reportagem". Observa-se um semi-simbolismo ${ }^{7}$ ou simbolismo "cristalizado": qualquer coisa que a câmera destaque é, e deve ser, valorizado.

Outro ponto sempre lembrado pelos teóricos do cinema é que um close-up de um rosto “acentua ao máximo a ação emocional”, como lembrava, já no começo do século passado, Hugo Munsterberg (In: XAVIER, 1982, p. 47). Cotidianamente, observar as expressões, notadamente a dos olhos, é uma maneira de investigar as "reais intenções" de alguém. O que a câmera faz, ao dar um close-up no rosto de Trinity, é deixar para ao público essa investigação. Em outras palavras, adquire-se um saber no close-up, mas essa função é secundária em relação ao impacto afetivo e à valorização imposta ao telespectador pela aproximação com uma pessoa ou objeto apresentado nesse plano.

Pensemos agora no plano oposto, o plano geral, que maneja, por outro lado, uma dimensão mais inteligível do que sensível. O plano geral "normalmente [...] é utilizado para apresentar todos os elementos da cena. [...] Além disso, através de um plano geral, consegue-se cobrir entradas e saídas das personagens e orientar o espectador sobre relacionamentos, movimentos e progressão dentro de cada cena do filme" (GAGE E MEYER, 199, p.78). Resumindo, no plano geral, o contato do público com o que é apresentado é mais da ordem inteligível. Diz Marcel Martin, em relação à "linguagem cinematográfica", que "reduzindo o homem a uma silhueta minúscula, o plano geral o reintegra ao mundo, faz com que as coisas o devorem, 'objetiva-o’” (1990, p.38). Há um efeito de conjunto. Somos solicitados a fazer relações entre objetos, pessoas e o espaço que ocupam.

O quadro que apresentamos em seguida mostra as possibilidades de significação manejadas pelos enquadramentos e efeitos de câmera, principalmente nesses dois "extremos", o close-up e o plano geral.

${ }^{7}$ É L. T. Hjelmslev que faz a primeira distinção entre sistemas simbólicos e sistemas semióticos. Os sistemas simbólicos - como os sinais de trânsito - são linguagens cujos planos de expressão e de conteúdo estão em conformidade total. A cada elemento da expressão corresponde um - e somente um - elemento do conteúdo. Para o estudioso não é vantagem distinguir o plano de expressão (lugar de trabalho de uma ou mais linguagens que vão, no mínimo, carregar os sentidos do plano de conteúdo) e o plano de conteúdo (lugar dos conceitos, ou onde o texto diz o que diz), já que ambos têm a mesma forma. Os sistemas semióticos são linguagens nas quais não existe conformidade entre os planos. É preciso distinguir e estudar separadamente expressão e conteúdo. As análises semióticas sobre artes plásticas (pintura, fotografia, cartazes), poesia, dança mostraram a importância de um terceiro tipo de sistema, os semisimbólicos ou poéticos, que se definem não mais pela conformidade entre elementos isolados dos dois planos, mas pela relação entre categorias do plano da expressão e categorias do plano de conteúdo, que criam uma espécie de micro-código. 
Fig. 3:

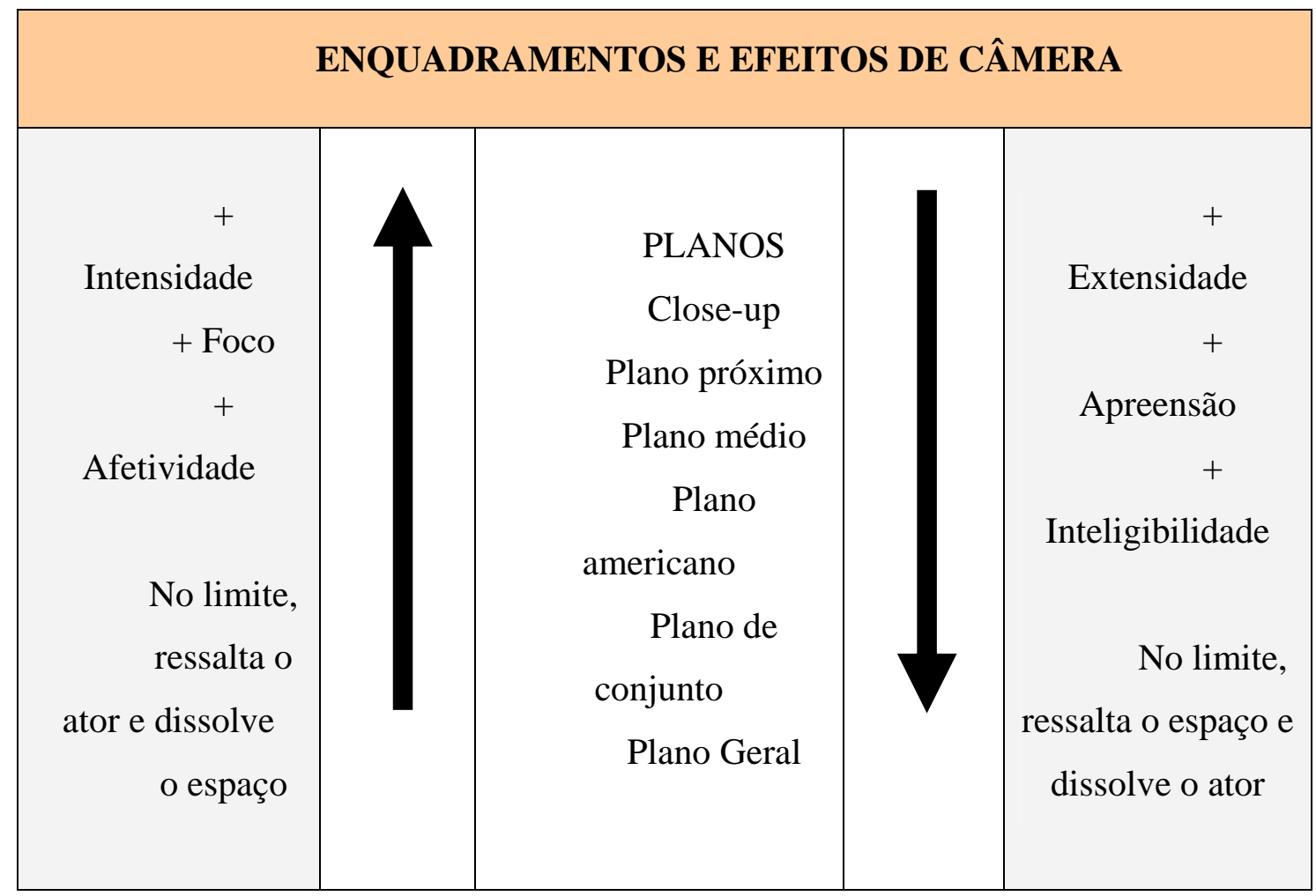

Fontanille afirma que "a tomada de posição de um sujeito acontece na forma de um foco que orienta o fluxo de atenção - e de uma apreensão, que delimita o domínio de pertinência [...]" (2003, p. 35). ${ }^{8}$ O foco pressupõe um sujeito mais ou menos tenso, mobilizado, afetado pela presença de algo que lhe reclama sentido. Ao mesmo tempo, a apreensão é o momento de passagem da percepção para a significação. O "mundo exterior" cria uma correspondência no mundo "interior", com a passagem do intenso para o extenso, da tensão para o relaxamento.

As concepções de foco semiótico e de foco de câmera - o close-up - são perfeitamente compatíveis. Ambas mostram o engajamento perceptivo do sujeito na forma de curiosidade, tensão, disforia. A apreensão pode ser relacionada, no caso do nosso trabalho, não só ao uso dos planos mais gerais como também ao processo inteiro vivido por um sujeito, que, atraído pela história do filme, deve passar da situação de não ter um saber desejado (disjunção) para a de

\footnotetext{
${ }^{8}$ No original: “[...] La 'prise de position' que détermine le partage entre expression et contenu deviant le premier acte de l'instance de discours, par lequel elle instaure son champ d'enonciation et sa deixis. Cette 'prise de position' se décline em deux actes, comme nous l'avons déjà suggéré, d'un côté la visée, qui dirige et oriente le flux d'attention, et de l'autre la saisie, qui délimite lê domaine de pertinence [...]."
} 
sujeito com esse saber (conjunção). Ao obter a compreensão, ao ter o quadro todo, o sujeito passa da tensão para o relaxamento, da insatisfação para a satisfação.

Os planos intermediários constroem sentidos de maneira proporcional, também em relação ao afastamento ou à aproximação de um objeto (que pode ser uma pessoa, um anel, uma sala). É por isso que o plano médio e o plano americano quase se apresentam como uma "justa medida" de enquadramento e simulam um tipo de contato mais neutro que temos com pessoas em nosso cotidiano.

É possível questionar: e nos casos nos quais temos uma tomada em plano geral de alta voltagem, ou seja, de forte impacto, como as máquinas entrando em Zion, por exemplo, em Matrix Revolutions? É importante dizer que o quadro se refere a formas de enquadramentos que são imaginadas, somente como exercício teórico, hipoteticamente descontextualizadas. Cada plano em uma tomada, no entanto, sempre está conectado a outros. Se pensarmos em um ângulo aberto de câmara com forte impacto afetivo - caso ainda de alguns momentos da briga final entre Neo e Smith em pleno ar em Revolutions, - vamos observar um ponto interessante: trata-se do que poderíamos chamar de "plano geral de clímax". Esse plano se apóia em toda uma história e mostra ápices narrativos. A tensão da entrada das máquinas em Zion supõe conhecimento de toda a narrativa anterior, que o público reconstrói, muitas vezes, numa fração de segundo: a existência da cidade e de sua proteção contra as máquinas, a batalha que deve acontecer, a invasão que pode significar aniquilamento. O impacto, portanto, depende totalmente das informações cedidas pela narrativa. Só assim esse tipo de plano tira o máximo proveito em termos de tensão. Para entender como esse plano isolado é mais de ordem inteligível, basta imaginar um filme começando com a mesma cena. Como não se tem ainda acesso à narrativa, o plano só vai cumprir sua missão de gerar informação (um saber) e alguma curiosidade (um querer-saber).

Outro ponto interessante é que teóricos de cinema e de vídeo falam da existência de uma câmera subjetiva e de uma câmera objetiva. A câmera objetiva é "a filmagem da cena de um ponto de vista de um público imaginário" (GAGE E MEYER, 1991, p.89). Esse é o recurso mais comum no cinema, e também em Matrix. A filmagem em câmera subjetiva, ao contrário, é rara. "Dizemos que uma câmera é subjetiva quando ela é colocada na posição que permite filmar do ponto de vista de uma personagem em ação durante determinada cena” (ibid., p.88). Como relacionar essas observações com a teoria da enunciação? Temos aí novos complicadores na categoria de pessoa desse tipo de discurso. A câmera subjetiva instaura um actante da enunciação e mostra a existência de uma desembreagem actancial enunciativa bastante particular. Em Matrix, o enunciador está 
mais interessado em uma decodificação rápida. O efeito geral buscado é, do ponto de vista dos planos de filmagem, mais enuncivo.

\section{Montagem e o domínio do tempo}

Apesar da importância das categorias espaciais na análise do plano de expressão cinematográfico, devemos insistir que são as categorias temporais que determinam as formas de sincretismo mais importantes entre conjuntos significantes. Em outras palavras, a organização das relações entre plano de expressão e plano de conteúdo ocorre em função do tempo, pois um filme se dá predominantemente na forma de um fluxo. No cinema, a edição ou montagem comanda os intervalos de tempo e as posições no fluxo temporal dos fragmentos, gerando importantes efeitos de sentido.

Marcel Martin (1990, p. 148) cita uma reflexão de J.-P. Chartier que mostra a importância da montagem dos planos para o nosso trabalho:

\footnotetext{
Um plano não é percebido do início ao fim do mesmo modo. Primeiramente é reconhecido e situado: corresponde, digamos, à exposição. Então intervém um momento de atenção máxima em que é captada a significação, a razão de ser do plano - gesto, palavra ou movimento -, que faz progredir a narrativa. Em seguida, a atenção diminui e, se o plano se prolonga, advém um instante de aborrecimento, impaciência. Se cada plano for cortado exatamente no momento em que diminui a atenção, sendo substituído por outro, o espectador permanecerá constantemente atento e diremos que o filme tem ritmo. O que chamamos ritmo cinematográfico não é, portanto, a mera relação do tempo entre planos, é a coincidência entre a duração de cada plano e os movimentos de atenção que desperta e satisfaz. Não se trata de um ritmo temporal abstrato, mas de um ritmo de atenção.
}

Não se pode falar em gerenciamento do nível de atenção do público e em significação no cinema sem pensar que o ritmo está bastante ligado à edição, à percepção de tempo na maneira de apresentar os conteúdos. Um das estratégias mais importantes para um bom ritmo se relaciona ao manejo do tempo aspectual, que converte a temporalidade da narrativa em um processo discursivo e cria o chamado "tempo psicológico", ou seja, a sensação de que um trecho - ou o filme inteiro - 
passa rapidamente ou lentamente. A missão do tempo aspectual é a de sobrepor-se à sensação de tempo cronológico do telespectador.

A alta carga de informação visual das cenas - e a necessidade de valorizar determinados momentos - fez de Matrix uma trilogia que trabalha com o recurso de câmera lenta ou superlenta ${ }^{9}$ intercalado com o andamento normal. A lentidão é uma marca de valor das cenas de maior tensão, notadamente das perseguições, lutas e tiros. É, em termos simples, o "esticamento" da tensão para maior contato público/ação.

Filmes de entretenimento manipulam um tipo importante de desenvolvimento temporal. Voltamos aqui a falar do tempo sensível, do tempo sentido pelo espectador. Podemos observar um andamento rápido, baseado em um grande número de tomadas, com cortes frenéticos, muitas vezes que fracionam um único segundo. Segundo o dicionário Aurélio, andamento, em música, é "o grau de velocidade que se imprime à execução de um trecho (grifo nosso) musical". Pensemos numa cena de 15 segundos. Se ela tiver 10 cortes parecerá mais rápida do que se tiver cinco, mesmo se mostrar exatamente a mesma ação nos mesmos 15 segundos. E o que muito nos interessa: há uma grande chance da cena de 10 tomadas concentrar mais a atenção do que a de cinco. Temos aqui, portanto, um dos dispositivos principais de produção de atenção e do tão necessário laço filme/público.

Já o andamento lento, não por acaso, refere-se a momentos de tensão narrativa, de dúvida sobre a competência do herói e de seu grupo. Tatit (2001, p.35), por exemplo, em análises musicais, lembra que

o universo passional do sujeito alimenta-se de duração. Precisamos de tempo para a configuração do nosso mundo sensível e um dos recursos mais comuns para a produção de durações nos textos é a gradação [...], já que desacelera o andamento e recupera, assim, parte do continuum perdido nas descontinuidades intelectivas.

Afirmamos que a sintaxe do cinema é o domínio de dois recursos principais, de câmera e de edição. A necessidade de manipulação do ritmo para prender a atenção do público mostra que a edição, notadamente nos filmes para o grande público, é "o chefe da hierarquia” nesse tipo de

\footnotetext{
${ }^{9}$ Tratamos essa questão como parte da edição, e não como recurso da linguagem de câmera, já que pode tanto ser gerada pelo equipamento como simulada em computadores, na fase final de montagem.
} 
sistema semiótico. Em outras palavras, a coerção de ritmo para um diretor é mais impositiva do que modos de enquadramentos na construção de um filme.

\section{Sem tempo para pensar}

O ritmo cinematográfico se relaciona com o filme, com o todo, e, por meio da montagem, explora um tipo de efeito importante de aspectualização: a sensação de rapidez ou lentidão por meio de acelerações e desacelerações. Com a edição, manipula-se o tempo necessário para o público pensar (ou encaixar plano de expressão e plano de conteúdo, na concepção de Fontanille) e dar ordem aos estímulos. Em Matrix, a montagem cria um ritmo, um tipo de sucessão de tomadas tão diverso e intenso que, na maioria dos momentos, o público só consegue vivenciar o impacto de uma emoção. Quando tenta elaborar determinado estímulo, o filme pode lhe dar outro, e assim por diante.

Para explicar melhor, vamos mostrar algumas contribuições de Fontanille e Zilberberg e, que propõem um "esquema afetivo para investigar os sentidos dos "afetos", palavra aqui entendida como termo complexo que, como um grande guarda-chuva, abrange todas as variações de estados de alma. A emoção, pontual, intensa, estaria no início. Ao se "alongar", ao ganhar extensidade na maioria das situações cotidianas, vira inclinação (ou afeição), depois, paixão e finalmente sentimento (2001, p. 281). ${ }^{10}$ A semiótica, portanto, desenha certas fronteiras entre estados afetivos que falantes do português não raras vezes denominam da mesma maneira ou misturam em diferentes gradações.

Ensinam Fontanille e Zilberberg que a passagem da emoção para a fase seguinte, a de inclinação, pode ser descrita como uma "explosão controlada". Isso quer dizer que, se alguém recebe o impacto da emoção, num primeiro momento não consegue nem distinguir se o que causou o choque gera atração ou repulsa. O "encaixe" entre expressão e conteúdo é precário, está em pleno andamento. A inclinação pode dar lugar à paixão, e depois, ao sentimento. Os dois semioticistas franceses afirmam que, no esquema proposto, as fases iniciais, da emoção e da inclinação, ocupariam o lugar da "somação", grosso modo, do corpo "agindo" e fazendo a mediação entre o sujeito e os fenômenos do mundo que se dão a sentir. As fases posteriores, da paixão e do sentimento, vinculam-se a uma "resolução", ou seja, à busca do objeto pelo sujeito e os conflitos que ele vai viver relacionados ao sucesso ou fracasso. É bom afirmar que o sujeito

\footnotetext{
${ }^{10}$ Inclinação, no português, só admite a tradução francesa - de "movimento afetivo, espontâneo, para um objeto ou um fim" - no sentido figurado, segundo o Aurélio. Esse é o sentido de inclinação utilizado neste trabalho.
} 
também mobiliza uma dimensão inteligível a partir da paixão e do sentimento, ou seja, ele reflete sobre os próprios sentimentos e como satisfazê-los ou não. ${ }^{11}$

Em objetos sincréticos como o cinema, quanto maior o ritmo de cortes, mais se ficará na dimensão emotiva, sensível, em outras palavras, o espectador não terá tempo de "axiologizar", ou remeter o que vê ao seu código de valores. Há várias "bobagens" em Matrix. A maior incongruência, já apontada por cientistas, é que o corpo humano é um gastador de energia. Jamais seria uma pilha. As máquinas, por exemplo, poderiam explorar a energia nuclear. Todas essas conjecturas, que arrasam a verossimilhança do filme, em um gênero cuja coerção maior é parecer científico, não são feitas pelo espectador por absoluta falta de tempo. Ele não tem um segundo para pensar. $^{12}$

\section{Considerações finais}

Para aprofundar a discussão sobre o fenômeno do sincretismo semiótico no cinema padrão Hollywood, procuramos mostrar, com exemplos da trilogia Matrix, a existência de uma sintaxe do cinema, dominada pela coerção temporal, de acontecer na forma de fluxo, que pode ser entendida como o uso relacional dos recursos de câmera e de edição, que têm a missão última de administrar como o público deve sentir e reagir, evidenciando ou desvalorizando certos aspectos do roteiro. Definem assim as relações entre outros conjuntos significantes, as formas de percepção de valores, momentos de tensão e de euforia/disforia da narrativa.

De tanto ver filmes, desde muito cedo assimilamos as regras da sintaxe cinematográfica caso dos sentidos dos planos de câmera, por exemplo - assim como, naturalmente, aprendemos a falar. Acreditávamos, em um primeiro momento, que essas relações eram semi-simbólicas,

\footnotetext{
${ }^{11}$ Em Tensão e Significação, Fontanille e Zilberberg afirmam que "uma paixão é [...] uma configuração [...] em que as correlações são ao mesmo tempo inteligíveis e sensíveis." E completam: "Na verdade, a partir do momento em que deixamos de lado uma abordagem moralizada da paixão, somos levados a ficar com tal definição e a abandonar as oposições clássicas entre a razão e a paixão (a paixão é uma forma de racionalidade discursiva), entre a ação e a paixão (a ação é uma redução da complexidade discursiva) e mesmo entre a natureza (passional) e a cultura. [...] De certo modo, vivenciar uma paixão seria mesmo conformar-se a uma identidade cultural e buscar significação de nossas emoções e afetos na sua maior ou menor conformidade às taxionomias acumuladas em nossa própria cultura". (2001, p. 298, 299).

${ }^{12}$ Há também a questão do impacto: mostrar a pilha e compará-la com um ser humano aprisionado por uma máquina é muito mais forte cinematograficamente do que qualquer outra explanação mais "científica" para preencher essa incoerência, como as propostas por Lloyd, P. B. em Falhas na Matrix... e como repará-las, In: A Pílula Vermelha Yeffeth, G. (org). Diz o autor que as máquinas poderiam aproveitar "a capacidade cerebral humana não-utilizada como um processador múltiplo colossal para controlar as reações de fusão nuclear" (p.122). Basta imaginar Morfeus explicando isso para Neo e para o público para entender porque se escolheu uma pilha no lugar da verossimilhança científica.
} 
definidas não mais pela conformidade entre elementos isolados dos dois planos, mas pela relação entre categorias do plano da expressão e categorias do plano de conteúdo, que criam uma espécie de micro-código. Nossos estudos sobre semióticas sincréticas evidenciaram, no entanto, a existência de semi-simbolismos "cristalizados", ou seja, que de tão repetidos viraram quase símbolos, como a câmera girar rápida sobre o eixo significar somente "confusão". Preferimos, então, estudar essas relações na forma de uma sintaxe do discurso cinematográfico, ou como a própria especificidade da linguagem cinematográfica - marcada pelo uso da câmera e da edição - e deixar a observação sobre semi-simbolismo restrita a fenômenos específicos de cada texto. É o caso do verde e do preto utilizados na trilogia remeterem à idéia de Matrix.

Tentamos evidenciar também que os estudos sobre os impactos ideológicos de textos cinematográficos devem levar em conta os efeitos da edição sobre a percepção dos valores pelo público. Procuramos mostrar que certas estratégias, como dar ou não tempo para o espectador refletir numa cena, determinam o que se pode chamar de "modulações" dos conteúdos. É a edição que controla o contato público/assunto das tomadas e, portanto, vai gerenciar as relações entre planos a partir dos interesses do enunciador. Quando cede mais tempo para uma tomada ou cena, por exemplo, maneja uma relação cessão de tempo - valor - atenção. Ao mesmo tempo, a fragmentação pode impedir a categorização de uma experiência em um sistema de valores. E incongruências, contradições, paradoxos ganham ares de verdade ou realidade porque o espectador não tem tempo para pensar.

\section{REFERÊNCIAS BIBLIOGRÁFICAS}

BARROS, D. L. P. Teoria do discurso: fundamentos semióticos. São Paulo, Atual, 1988. Texto e Imagem In: Linguagens. Porto Alegre, [s.n.], 1986.

COMPARATO, . Arte e técnica de escrever para cinema e televisão. Rio de Janeiro: Nórdica, 3a. ed, 1983.

FIORIN, J. L. Elementos de Análise do Discurso. São Paulo: Contexto, 1999. As astúcias da enunciação: As categorias de pessoa, espaço e tempo. São Paulo, Ática, 1996. 
FOnTANIlle, J.; ZILBERBERG, C. Tensão e significação. São Paulo: Discurso Editorial: Humanitas/FFCHL/USP, 2001.

- Sémiotique du Discours. Paris: Pulim - Collection: Nouveaux Actes Semiotiques, 2a. ed., 2003, p. 20.

GAGE, L. D.; MEYER, C. O filme publicitário. São Paulo: Atlas, 2ªed., 1991.

GREIMAS, A. J. Semiótica Figurativa e semiótica plástica. In: Significação. Araraquara: Centro de Estudos semióticos, 1984.

. Sémiotique: Dictionnaire raisonné de la théorie du langage II. Paris: Hachette, 1986.

IRWIN, W. (ORG.). Matrix - Bem-vindo ao Deserto do Real. São Paulo: Madras, 2003.

MARTIN, M.. A linguagem do Cinema. São Paulo: ed. Brasiliense, 1990.

MUNSTERBERG, H. A atenção - In A experiência do cinema. Xavier, I. (ORG) Rio de Janeiro: Graal, 1991.

SENAC - Manual de Vídeo do Centro de Centro de Comunicação e Artes. São Paulo: [s.d.].

TATIT, L. Análise semiótica através das letras. São Paulo: Ateliê Editorial, 2001.

YEFFETH, G. (ORG). A Pílula Vermelha: questões de ciência, filosofia e religião em Matrix. São Paulo: Publifolha, 2003.

WATTS, H. On câmera: o curso de produção de filme e vídeo da BBC. São Paulo: Summus Editorial, 1990 
CASA Vol. 3.n.1, agosto de 2005

WAIN, G. Como filmar. Lisboa: Prelo Editora, Lisboa, $3^{\mathrm{a} e d ., ~[s . d .] . ~}$ 